\title{
DE TROONSOPVOLGING
}

\author{
VAN DE
}

\section{MUSELMANSCHE VORSTEN.}

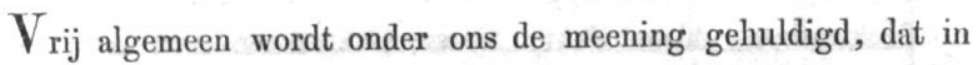
den Indischen Archipel een der zonen of nabestaanden yan den laatsten vorst tot zijn opvolger behoort te worden gekozen, en dat daarbij zooveel mogelijk de godsdienstige wetten, instellingen en gebruiken der inlanders moeten worden in het oog gehouden. Die meening doet echter haar kracht slechts gelden voor zoover het betreft vorsten, die geoordeeld worden, hetzij geheel hetzij gedeeltelijk, den Islam aan te hangen; zij strekt zich niet uit tot die vorsten, welke nog op de voorvaderlijke, polynesische, wijze heerschappij voeren over volken, waarop de Islam nog geen, of ten minste zeer weinig, vat heeft gekregen. Maar ook zoo beperkt, is er een nader onderzoek dienaangaande noodig, want, en dit verdient vooral opmerking, de wetgeleerde boeken van den Islam kennen geen ERF-opvolging van den troon. Het onderwerp wordt ongetwijfeld wel belangrijk en het bedoelde onderzoek dus wel nuttig gerekend. Om dat onderzoek mogelijk, ten minste gemakkelijk, te maken, zal men in de eerste plaats moeten weten wat er omtrent de troonsopvolging van de Muselmansche vorsten regtens is: daarna zal men eerst kunnen nagaan of ook deze aangelegenheid, zoo als met andere wel is geschied, door een oppervlakkige waarneming onvolledig bekend en dientengevolge verkeerd is voorgesteld geworden; of zij door polynesischen of europeschen in- 
vloed zóó ver is afgeweken van haren oorsprong, dat zelfs een van hare grondtrekken geheel is veranderd. De inhoud van de wetgeleerde boeken op dat punt verdient derhalve de eerste plaats.

Het regt van de Mohammedanen is historisch ontwikkeld, niet philosophisch; vooral ten opzigte van het onderwerp, dat hier zal worden behandeld, is dit volkomen waar. Nergens vindt men daarbij een regeling naar hetgeen volgens abstracte begrippen goed scheen, altijd wordt tot rigtsnoer genomen hetgeen bij de troonsbestijging van de vier eerste opvolgers van Mohammed, Aboe Bakr, Omar, Othman en Ali, is voorgevallen. Dit dient dus vooraf bekend te zijn.

Den zevenden of achtsten Junij 632 overleed Mohammed, zonder eenige bepaling te hebben gemaakt over de troonsopvolging, hoewel hem de dood geenszins onverwacht kwam. Hij liet geen mannelijke nakomelingen na; zijn naaste verwanten waren Ali, zijn neef en schoonzoon, en Aboe Bakr, de vader van zijn geliefde vrouw Aïsja. Moeijelijk is de reden op te geven waarom Mohammed voor het door hem gestichte rijk geen opvolger aanwees of aanried. Misschien werd hij op het ziekbed daarin verhinderd door zijn omgeving, die een beslissing vreesde, welke niet met haar verlangen overeenkwam; misschien wijfelde hij zelf in de keus tusschen den echtgenoot van zijn geliefde dochter, tot wien zijn hart trok, en den vader van Aïsja, dien zijn doorzigt hem aanwees; misschien ook vermeed hij, tot den laatsten ademtogt, van zijn dood te spreken, want zeker is het, dat vele Arabieren hem als onsterfelijk beschouwden. De anspraak op de troonsopvolging van deze twee praetendenten was niet alleen daarop gegrond, dat zij waren de verwanten van Mohammed en zijn oudste, vrienden, maar ook dat zij behoorden tot het adellijke geslacht der Koreisjiten. Reeds vóór Mohammed̀ waren hun voorouders met de voornaamste waardigheden en ambten bekleed geweest in Mekka, dat 
door de bedevaart, die daarheen werd ondernomen, een zekere heerschappij had verkregen over het geheele schiereiland. De burgers van Mekka, die langzamerhand zich in grooten getale sedert het welslagen van den Islam en vooral sedert de verhuizing van Mohammed in Medina hadden gevestigd, dachten terstond, al was het maar alleen uit voorliefde voor hun stamgenooten en landslieden, aan Ali of aan Aboe Bakr, toen er kwestie was om een opvolger voor Mohammed te kiezen. Daarentegen wilden de oude ingezetenen van Medina, die gedeeltelijk slechts ongaarne den Profeet hadden gehoorzaamd, niet langer een vreemdeling, gesproten uit een geheel anderen stam, volgen. Zij besloten derhalve om terstond na Mohammed's dood een man uit hun midden tot vorst van den Islam, of ten minste tot hun opperhoofd te kiezen. Reeds hadden zij zich in cen huis vergaderd om aan hun Hoofd, Sa'ad Ibn Ibada, de heerschappij van het islamitisch rijk op te dragen, toen plotseling Aboe Bakr, vergezeld van Omar, Aboe Obeida en eenige anderen van zijn partij, binnentrad en zoowel met plaatsen uit den Koran als met andere uitspraken van Mohammed trachtte te bewijzen, dat het chalifaat toekwam aan een Koreisjiet, die met den Profeet was verhuisd, en dat slechts zoo iemand verwachten mogt dat hij door geheel Arabië zou worden erkend. Hij stelde daarop Aboe Obeida en Omar tot chalif voor, maar beiden verklaarden hem waardiger voor de heerschappij en huldigden hem terstond. De welsprekendheid van Aboe Bakr en van zijn vrienden zou waarschijnlijk echter niet zoo gemakkelijk de overwinning hebben behaald, indien Ali in die vergadering tegenwoordig was geweest, of indien de burgers van Medina eenstemmig hadden gedacht. Onmogelijk echter werd een langdurige tegenstand voor de aanhangers van Sa'ad, toen de Aslamiten, die verwant aan en verbonden met de Koreisjiten waren, kwamen aanstroomen, alle toegangen versperden en onmiddellijk Aboe Bakr tot chalif uitriepen ${ }^{1}$.

1 WeIL, Geschichte der Chalifen, tom. I, pagg. 1-5. 
Aboe Bakr bleef gedachtig hetgeen na Mohammeds dood ten gevolge van de onbesliste troonsopvolging was voorgevallen en wenschte nog bij zijn leven die kwestie ten gunste van Omar te beslissen. Daarom liet hij, tijdens zijn ziekte, de aanzienlijkste en invloedrijkste vrienden van den Profeet tot zich komen en schilderde hun Omar als een degelijk en krachtig man, die het best van allen in staat was om de heerschappij naar behooren te voeren. Toen hem door een van hen werd opgemerkt, dat Omar hardvochtig was, antwoordde hij: “Omar was "slechts zoo streng, omdat ik te zacht was; als hij eens alleen "heerscht, zal hij wel zachter worden, want dikwerf trachtte "hij mij tot bedaren te brengen, als hij merkte dat ik tot "strengheid geneigd was; alleen als ik te zacht was, toonde hij “zich hardvochtig." Een ander voegde hij toe: "ik weet zeker “dat Omar's innerlijk beter is, dan zijn uiterlijk schijnt.” Beiden verzocht hij om niets van zijn voornemen te doen blijken. Eerst toen de Hoofden der Muselmannen, waaronder er misschien velen waren, aan wie hij hoop op de opvolging had gegeven, vergaderd waren, vroeg hij: “Wilt gij dat ik u een opvolger aanwijs? “Bij God, ik zal het doen na rijp beraad en zonder een mijner "verwanten te bevoorregten." Nadat zij gezworen hadden hem te zullen gehoorzamen, noemde hij Omar Ibn Chattaab, wiens verheffing tot chalif hij reeds vooraf door Othman had laten op schrift stellen '.

Omar wilde het ontluikende rijk tegen burgeroorlog behoeden; daarom wees hij bij uiterste wilsbeschikking Abd ErRahmaan, als den waardigsten Muselman, voor het chalifaat aan. Toen deze weigerde, benoemde hij de zes oudste vrienden van Mohammed, namelijk Ali, Othman, Abd-Er-Rahmaan, Zobeir, Talha en Sa'ad Ibn Wakkaaz, tot candidaten voor de opvolging: hij, die van deze zes de meeste stemmen zou verkrijgen, zou opvolger worden. Deze beschikking zou echter den burgeroorlog niet hebben voorkomen, indien Abd-Er-Rah-

1 L. l., pagg. 49 en 50. 
maan eigenlijk niet meer leider en voorzitter der kiezers, dan medestemmende was geweest: hij stemde dan ook alleen maar mede, omdat één van de vijf kiezers twijfelde of afwezig was. Ten einde de keuze niet te lang zou worden uitgesteld en tevens de kiezers ongestoord zouden kunnen beraadslagen, moesten vijftig man de vergadering bewaken, met last om geen vreemde tot het huis toe te laten en geen kiezer om het te verlaten, ingeval men op den derden dag nog tot geen resultaat zou zijn gekomen. Ook zou geen van de candidaten, tot dat de keus zou zijn afgeloopen, als imaam (d. i. voorganger in het gebed) mogen fungeren, om te voorkomen, hetgeen met Aboe Bakr na den dood van Mohammed was geschied, dat iemand uit dat imamaat een regt op het chalifaat ontleende '. Toen nu na den dood van Omar de candidaten bij elkander kwamen en Ali ook daartoe werd uitgenoodigd, zeide zijn oom Abbaas tot hem: "neem geen deel aan de keus, want op u "valt zij toch niet: Omar beminde de Hasjimiten niet en "heeft $\mathrm{u}$ onder de anderen slechts voorgesteld, om door uwe "aanwezigheid aan de keus, die op een ander vallen zal, des "te meer gewigt te hechten." Ali geloofde echter niet aan de mogelijkheid, dat aan een ander de voorkeur boven hem zoude kunnen worden gegeven, en begaf zich naar de woning van Aïsja, waar de keuze zou gedaan worden. Twee dagen verliepen er in ijdele debatten; ieder trachtte zijn verdiensten te doen uitkomen en zijn aanspraak op het chalifaat te doen gelden of die van een ander te verwerpen; dikwijls werd de strijd zó hevig, dat Aboe Talha, het Hoofd van de vijftig wachters, tusschen beiden moest komen. Toen zij op den derden dag weêr bij elkander waren, zeide Aboe Talha tot hen: “heden mag "niemand dit huis verlaten, voor dat gij tot een besluit zijt "gekomen omtrent de keus van een chalif." Ook dien dag liepen de debatten, even als de beide vorige dagen, doch AbdEr-Rahmaan zeide: “ik zie dat wij op die manier niet tot

2 L. 1. pagg. 129 en 130. 
"een eind komen, als een ieder alleen maar tracht zijn eigen "aanspraak te doen gelden. Is er dan niemand onder $u$, die, "even als ik, afstand doet van het chalifaat?" Niemand antwoordde. Nadat hij die vraag vijfmaal herhaald had en zij steeds onbeantwoord was gebleven, ging hij voort: "Ik wil u “het werk gemakkelijker maken: wilt gij beloven om dengeen, "dien ik tot chalif zal aanwijzen, als zoodanig te erkennen?" Allen antwoordden bevestigend, doch Ali stelde als voorwaarde, dat hij niet met voorliefde voor zijn stamgenooten zou beslissen: die voorwaarde nam Abd-Er-Rahmaan aan, met de verklaring, dat hij geen baatzuchtige oogmerken had, omdat hij anders de heerschappij wel voor zich zou vragen. Daarna ging Abd-ErRahmaan in een hoek van de kamer en riep eerst Ali bij zich, tot wien hij zeide: "Gij, de neef van den Profeet, behoorende "tot het geslacht der Hasjimiten, beschouwt u als den eersten "Muselman en daarom het meest waardig de heerschappij te "voeren. Ik wil u dit toegeven; maar gesteld eens, dat de "keus niet op u viel, wien zoudt gij dan als den waardigste “beschouwen?" - “Dan zou ik voor Othman stemmen," zei Ali. Daarna werd Othman geroepen en hem een dergelijke vraag gedaan: hij zou dan voor Ali stemmen, hernam hij. Op dezelfde wijs ging het met Sa'ad en met Zobeir; de eerste stemde voor Ali, de laatste voor Othman. $\mathrm{Nu}$ stond Abd-ErRahmaan op en zeide: "Het blịkt nu dat de keus nog slechts "tusschen Ali en Othman wankelt: gaat nu naar huis! morgen "zal ik een van beiden huldigen." Waarschijnlijk was hij angstvallig en durfde hij niet op zijn verantwoordelijkheid te nemen hetgeen Omar zelf niet op zich had genomen: hij wilde eerst de gezindheid van het volk, of ten minste van zijn Hoofden, polsen en daarna beslissen. Den volgenden dag beklom hij den kansel en droeg de uiterste wilsbeschikking van Omar aan de gemeente voor; hij deelde haar mede het resultaat van hetgeen tot nog toe gedaan was, en spoorde aan om voor Ali of Othman uitspraak te doen. $\mathrm{Nu}$ ontstond hier een hevige strijgd tusschen de Mahzoemiten, waartoe Othman behoorde, en de Ha- 
sjimiten, de stamgenooten van Ali. Om daaraan een einde te maken, riep $\Lambda$ bd-Er-Rahmaan uit: “houdt u een oogenblik stil, “gij Muselmannen! opdat ik naar mijn overtuiging kan beslis"sen." Nadat het stil was geworden, riep hij Ali tot zich en zeide tot hem: "Beloof bij God, den Verhevene, dat gij over “de Muselmannen wilt heerschen naar de voorschriften van de "goddelijke openbaring, dat gij het leven van den Prófeet tot "rigtsnoer wilt nemen, en dat gij de grondstellingen van de beide "voorafgegane chalifen wilt handhaven." Ali antwoordde: "ik "zal mij onvoorwaardelijk onderwerpen aan de goddelijke schrift “en de mondelijke leer van den Profeet naleven: de grondstel“lingen van mijn beide voorgangers echter zal ik, zooveel ik kan, "trachten trouw te blijven." Dit antwoord, hetwelk in zekere mate een protest tegen vele handelingen van Omar en Aboe Bakr inhield, mishaagde aan Abd-Er-Rahmaan, die weP inzag, dat voor het behoud van eendragt en onbeperkte gehoorzaamheid een volstrekt vereischte was om een zekere onfeilbaarheid aan de chalifen toe te kennen. Daarna riep hij Othman en deed hem dezelfde vraag, die daarop onverwijld bevestigend antwoordde. Abd-Er-Rahmaan gaf hem den handslag (d. i. de oude vorm van huldiging); dit voorbeeld volgde de geheele gemeente, hoewel Ali en zijne volgelingen dat oordeel voor onregtvaardig verklaarden ${ }^{1}$.

Nadat Othman vermoord was, verliep er een geheele week, eer er een opvolger werd gekozen. De rebellen begaven zich terstond naar Ali en riepen hem tot chalif uit, doch hij weigerde zijn hand tot huldiging uit te strekken naar menschen, die zich met bloed hadden bevlekt; hetzelfde zouden Talha en Zobeir, die vervolgens gekozen waren, gedaan hebben. Eerst den volgenden vrijdag, toen ook de burgers van Medina aan Ali de heerschappij opdroegen om aan de bestaande regeringloosheid een einde te maken, verklaarde hij zich bereid om het chalifaat over te nemen, als Talha en Zobeir hem zouden hul-

1 L. I. pagg. 149-155. 
digen. Beiden werden daartoe gedwongen en daarna trad Ali als chalif op ${ }^{1}$.

Uit hetgeen ons de geschiedenis aangaande dit punt leert, zien wij, dat in de eerste tijden van den Islam de chalif op tweederlei wijs den troon besteeg. Bij ontstentenis van een opvolger, zoo als na den dood van Mohammed het geval was, werd hij benoemd door een soort van volkskeuze; in de andere gevallen, zoo als bij Aboe Bakr en Omar, wees de soeverein zijn opvolger aan of designeerde den toekomstigen chalif. De wetgeleerden hebben dit verschil streng in het oog gehouden en op die weinige gegevens een geheel stelsel van troonsopvolging gebouwd. Hetgeen daarover gelezen wordt in het Staatsregt van Maverdi '2, zal dat stelsel duidelijk voorstellen.

Ingeval er geen soeverein aanwezig is, worden de Muselmannen in twee soorten, de kiezers en de verkiesbaren, verdeeld: iedereen kan zich echter, zonder zonde te begaan, daaraan onttrekken.

Hij die tot de notabelen behoort, die bekend is met de regten welke de soeverein mag uitoefenen, en die genoeg oordeel en doorzigt heeft om den bekwaamsten tot soeverein te kiezen, wordt tot de kiezers gerekend.

Hij die behoort tot de notabelen, die een eigen uitspraak in regtszaken mag geven, die gezond van zintuigen (goed van gehoor, gezigt en spraak) en van ledematen is, die met oordeel kan besturen en het meest in het algemeen belang kan handelen, die dapper is in het verdedigen tegen en in het aanvallen van den vijand, en hij die tot de Koreisjieten behoort, is verkiesbaar.

1 L. 1. pagg. 191 en 192.

2 Maverdii Constitutiones Politicae, (Ahkaam 's-soltanijat). Ed. Enger. Bonn, 1853. 
De meerderheid van de kiezers uit elke landstreek wordt door sommigen gevorderd om de keuze te bepalen. Anderen houden het getal van vijf, weer anderen dat van drie, voor voldoende. Er zijn zelfs die beweren, dat de keus kan geschieden door één persoon.

De kiezers zijn in hun keuze beperkt tot dengeen, die aan de meeste van de gevorderde vereischten voldoet. Ingeval alle verkiesbaren daarin aan elkander gelijk staan, wordt de oudere van jaren gekozen. Ingeval zij daarin van elkander verschillen, bijv. de een is geleerder en de ander dapperder, dan wordt degeen gekozen, waaraan op dat oogenblik het meest behoefte bestaat.

Als op elk van twee verkiesbaren een gelijk getal stemmen wordt uitgebragt, worden beiden volgens sommigen uitgesloten, volgens anderen toegelaten: sommigen van de laatstgenoemden willen dan tusschen beiden het lot laten beslissen, anderen de kiezers tusschen hen beiden laten kiezen.

Indien er in elk van twee verschillende landstreken een soeverein is gekozen, dan is de eerstgekozene de benoemde; bij gelijktijdige verkiezing zijn beide keuzen nietig en moet er, volgens sommigen, een van beiden of een ander op nieuw gekozen, volgens anderen, moet er tusschen beiden worden geloot. Er zijn ook die de voorkeur geven aan dengeen die in het land, waar de vorige soeverein is gestorven, is gekozen.

$\mathrm{Na}$ het uitbrengen van de keus, wordt de overeenkomst met den gekozene aangegaan door de kiezers, die daarna eerst door hen en vervolgens door het volk moet worden gehuldigd.

De soeverein heeft het regt om tot zijn opvolger aan te wijzen of te designeren dengeen, dien hij daartoe het geschiktst rekent, mits hij in zich vereenigt dé gewone vereischten, gesteld voor de vervulling van de soevereiniteit.

De gedesigneerde kan zijn iemand, die den soeverein bestaat of als familie in de opgaande of nederdalende linie, of als familie

III. (VIII.) 
in de zijlinie of die hem geheel vreemd is. In het laatste geval, als namelijk de gedesigneerde niet behoort tot de familie van den soeverein in de opgaande of nederdalende linie, kan de soeverein handelen geheel naar eigen zienswijze en behoeft hij bij het designeren de kiezers niet te raadplegen, zelfs behoeven zij bij de huldiging van hun goedkeuring niet te doen blijken. In het eerste geval, als namelijk de gedesigneerde is de zoon of vader van den soeverein, zijn er drie uiteenloopende gevoelens over de vraag of de soeverein zonder medewerking van de kiezers iemand designeren kan: volgens sommigen mag hij geen van beiden zonder die medewerking tot zijn opvolger aanwijzen, volgens anderen mag dit bij beiden wel, volgens nog anderen mag dit bij den vader wel, maar bij den zoon niet.

De gedesigneerde krijgt eerst regt op de soevereiniteit na den dood van den soeverein of nadat hij de regering heeft nedergelegd. Voor de geldigheid van het designeren is noodig, dat de gedesigneerde het heeft aangenomen tusschen de opdragt en den dood van den soeverein; volgens sommigen heeft hij na dat overlijden nog een behoorlijken tijd van beraad. Nadat de gedesigneerde de opdragt heeft aangenomen, kan hij niet worden afgezet, zoolang hij niet in den toestand komt, waarin een vorst de soevereiniteit verliest; zelfs wordt het ontslag, als de gedesigneerde het zelf vraagt, niet gegeven zoolang geen geschikte plaatsvervanger is gevonden.

De soeverein kan ook één of meer personen, mits een bepaald getal, kiezen, om de kiezers een keus uit hen te laten doen. Deze zijn dan gebonden tot het aangewezen getal, waaruit zij één moeten kiezen na den dood van den soeverein, of, als hij het goedvindt, bij zijn leven. De gekozene kan later weer een ander designeren, wien hij wil; hij is dan niet beperkt tot het genoemde getal.

De soeverein kan twee of meer personen, den een na dent ander, aanwijzen tot zijn opvolgers; alsdan wordt tot de soevereiniteit geroepen de eerstgenoemde van de gedesigneerden, die hij den dood van den soeverein in leven zijn. Degeen die op 
deze wijs soeverein is geworden, kan volgens de meeste wetgeleerden wederom een ander naar zijn verkiezing designeren, doch sommigen beperken hem tot zijn vroegere mederegthebbenden. In dit geval mogen de kiezers geen ander dan een van de gedesigneerden benoemen.

De leer van den Islam omtrent de troonsopvolging, die hier in groote trekken is medegedeeld, heeft in de praktijk den schijn van erfopvolging, omdat de vader wel steeds in de eerste plaats zijn zoon of naaste familie tot opvolger zal designeren. Ofschoon dit niet kan worden tegengesproken, bestaat er toch nog menig punt van verschil tusschen de Mohammedaansche troonsopvolging en de erfopvolging. Tk zal er een paar van noemen.

Bij erfopvolging berust het regt op den troon bij den zoon; in de Mohammedaansche troonsopvolging moet de vader hem eerst tot den troon roepen.

$\mathrm{Bij}$ erfopvolging is er geen spraak van goedkeuring door kiezers of keurvorsten: in de Mohammedaansche troonsopvolging, zoo als gebleken is, wel.

$\mathrm{Om}$ deze redenen scheen mij dit onderwerp belangrijk genoeg toe, om het in de laatste algemeene vergadering van ons Instituut ter sprake te brengen. Hetgeen daaromtrent werd opgemerkt door de Heeren J. L. B. Engelhard, J. G. A. Gallois en J. T. Willer, die mededeelden wat zij dienaangaande hadden waargenomen gedurende hun verblijf in Indië, als hoofden van verschillende gewesten, deed de wenschelijkheid uitspreken om, door plaatsing in onze Bijdragen, deze aangelegenheid te brengen onder de aandacht van degenen in Indië, die door nasporing daarover eenig licht kunnen verspreiden.

DELFT, Julij 1861.

S. $K$. 